\title{
Pressuring trading partners to adopt a business-to-business connectivity platform - stick or carrot?
}

\author{
Esko Penttinen \\ Aalto University School of Business, \\ Finland \\ esko.penttinen@aalto.fi
}

\author{
Tapani Rinta-Kahila \\ The University of Queensland, \\ Australia \\ t.rintakahila@uq.edu.au
}

\author{
Jukka Sihvonen \\ Aalto University School of Business, \\ Finland \\ jukka.sihvonen@aalto.fi
}

\begin{abstract}
The paper examines the impact of external pressure in the act of onboarding trading partners to business-tobusiness (B2B) connectivity platforms. Articulating different forms of external pressure (enticement and enforcement) and drawing on a survey of 121 organizations, it examines the effect of three enticement factors and three enforcement factors on firms' decision to adopt a B2B connectivity platform. In general, enforcement measures ("sticks") were found to be more effective than enticement ("carrots"). Two exceptions are presented: enticement works better than enforcement in persuading organizations with high invoicing intensity or heavy use of cloud technologies. The authors discuss the overall finding and theorize in light of the empirical study's context, wherein the platform generates asymmetric benefits to the trading partners (i.e., an organization receiving the transaction document delivered through the B2B connectivity platform harnesses most of the benefits). The findings' implications for research and practice are considered.
\end{abstract}

\section{Introduction}

Often, organizations invest in information system (IS) development and implementation without knowing whether they will be able to realize the benefits of the associated investments $[4,8]$. One prominent obstacle of reaping the benefits is a failure to onboard relevant stakeholders to use the implemented systems. Rejection of the systems implemented are well-known roadblocks recognized in the IS implementation literature, and finding ways to overcome them remains a highly relevant challenge for managers. Previous work has considered the topic at both the level of individual workers [1,21, 25] and entire organizations [3, 11]. Our work is focused on the organizational level.

The problem of non-use is accentuated in cases of organizational technologies that enjoy considerable network effects, as is the case with business-to-business (B2B) connectivity platforms. Since the value derived from using these technologies accrues in proportion with the number of users, a member of the network has reason to be active in persuading other organizations to join in and making sure they do so. Examples of systems in this category are telecommunication and messaging networks, payment systems [28], open-standard interorganizational information systems [41], and electronic platforms in general [30]. As for examples of failure, the Swedish government's recent attempt to implement an electronic business-reporting platform is a prominent case of an IS implementation that failed to deliver benefits and was ultimately discontinued [27]. The use of the platform, which enabled companies to submit their annual reports by means of eXtensible Business Reporting Language (XBRL), was not obligatory for companies, and it remained sparsely adopted. It was eventually abandoned because of its insufficient user base. A contrasting example comes from Denmark, where the use of a similar XBRL platform was mandated. It received strong acceptance from those required to use it and generated positive outcomes [20].

Whereas organizations can mandate that their employees use any system adopted [24], Imposing the use of B2B connectivity platforms on trading partners is far more complex [34]. The Danish example shows that adoption by other organizations may be guaranteed when the focal organization wields power rooted in formal authority [20], which government organizations often hold over private businesses. In B2B contexts, however, the focal organization often has no such power over the system's end-user organizations. This lack of authority calls for finding ways for the organization to persuade its partner organizations to adopt the relevant B2B connectivity platform.

In light of these issues, researchers have put considerable effort into improving our understanding of the diffusion factors associated with the deployment of technologies that have important network effects, and this work has led to the acknowledgment of external pressure as a prerequisite to such information systems' diffusion [26, 38]. However, instead of directly 
measuring the pressure experienced, prior studies have gauged pressure via generic proxies such as estimation of customers' and suppliers' technology adoption and the perceived influence over the focal organization [38]. That approach does not consider the effects of concrete pressuring actions, such as explicitly communicating a demand that the business partner adopts the B2B platform. In other words, the work thus far has focused on the effect of the environment's perceived pressure potential instead of the pressure actually experienced. Moreover, although the style of pressure is likely to affect its outcomes in various contexts, little is known of the effects of particular nuances and forms of external pressure. These may range from mere enticement efforts to strict enforcement and, ultimately, threats of discontinuing the business relationship. Motivated by the importance of attracting users to technological platforms that draw on network effects and bringing them aboard and by the apparent lack of studies probing the nuances of persuasion, we asked, "Can the objective of getting trading partners onto a B2B connectivity platform be better achieved through enticement or through enforcement?"

\section{Literature on external pressure}

Our objective was to study the effects of persuasion on organizational decision-making in the context of B2B connectivity platforms. To lay the groundwork for discussing the study and our findings, we will review the relevant literature (i) on the types of external pressure imposed by other organizations, (ii) on B2B connectivity platforms, and (iii) specifically addressing external pressure's role in persuading trading partners to adopt B2B connectivity platforms.

\subsection{Coercive forces - types of external pressure exerted on organizations}

Persuasion has traditionally been regarded as a communication process in which a persuader sends a persuasive message to a persuadee or group of persuadees with the intention of changing that audience's attitudes or behavior [14]. Empirical research on persuasion has most often focused on the influence of persuasion on individuals' attitudes, presuming that these attitudes, in turn, will have an effect on real-world behavior.

Within the organizational realm, institutional theory notes that organizations face diverse institutional pressures to conform to various rules and regulations in their attempt to earn legitimacy of existence [36]. Collectively, these institutional pressures contribute to interorganizational homogeneity [16], or institutional isomorphism [7]. Prior literature outlines three main processes through which this institutional isomorphism among organizations comes about: coercive, mimetic, and normative [7]. Mimetic isomorphism results from organizations imitating their successful counterparts, typically in response to uncertainty. Normative isomorphism stems from the emergence of shared values and practices within a profession. Finally, coercive isomorphism, at the heart of our study, stems from both formal and informal pressures exerted on organizations. Sometimes, the coercive institutional pressures are exerted on organizations by other organizations, and these pressures may be felt by the object of the pressure as force, as persuasion, or as invitations to collusion [7].

Drawing on the institutional-theory literature's discussion of these manifestations, so as to distinguish among the various forms of external pressure, we draw a distinction between two main types of persuasion in the context of organizational decision-making: gentle enticement efforts ("enticement" from here on) and coercive enforcement ("enforcement" from here on). The former involves subtle nudging and informing the organization's decision-maker(s) about the benefits of the technology with the aim of encouraging potential users in that organization to adopt and deploy the system in question. Thereby, enticement relies on the firm's natural willingness to deploy an information system that it expects to provide it with certain specific utility. Enforcement, on the other hand, can be seen as either a form of persuasion [12] or an alternative to persuasion [14]. It typically relies on a relatively dominant organization applying bargaining power to its less dominant business partners in the form of sanctions or implications thereof [15]. This characterization points to the importance of power as a vital antecedent to enforcement behavior.

With persuasion being prevalent in all facets of human life, it is studied extensively in most branches of the social sciences, and discussion of its various manifestations (e.g., enticement versus enforcement) can be found in various streams of academic literature. For instance, the concepts of enforcement and enticement resonate with political and policy research's notions of negative-restraining and affirmativepromoting governance tools [2]. The negative (restraining) tools comprise penalties, or "sticks," in the form of punishment, costs, and negative sanctions and/or threats of these, while the affirmative (promoting) tools apply incentives, or "carrots," through rewards, benefits, grants, tax exemptions, and (promises of) facilitative measures [2]. In research on cognition, dual-process models of persuasion such as the elaboration likelihood model (ELM) articulate two broad avenues to persuasion: the main one, on which 
those receiving the persuasion messages carefully process the arguments received, and a peripheral route, on which receivers rely on mental shortcuts as a means of reaching a conclusion [33]. One distinguishing factor between the two routes is the degree of engagement with the topic and the decision. As involvement rises, reliance on the peripheral route and related heuristics declines, and "close message processing" increases.

\subsection{B2B connectivity platforms}

A platform is "a business [...] enabling valuecreating interactions between external producers and consumers. The platform provides an open, participative infrastructure for these interactions and sets governance conditions for them" $[31, \mathrm{p} .5]$. The set of B2B connectivity platforms - labeled "transaction devices" [10] - is a specific collection of platforms that provide services that connect trading partners with regard to, for example, supply-chain documents such as tenders, orders, invoices, and payments. The recent surge of interest in open networking and data standards, such as XML (eXtensible Markup Language), has promoted the growth of connectivity platforms in multiple industries [31]. They can aid in companies' work to conclude and fulfill trading-related contracts, even when multiple platform providers are involved. Examples of this type of platforms include SAP Ariba, Tietoevry, and Tradeshift.

B2B connectivity platforms enjoy considerable network effects; i.e., the value of the network grows sharply as the number of nodes in it increases. Therefore, it is important for any focal firm to get its trading partners to use the connectivity services offered by the platform(s) it provides - i.e., to send and receive trading documents on that platform. Bringing them aboard in this sense has been termed "onboarding" in the context of B2B connectivity platforms [32]. But how to effectively trigger onboarding? Thus far, researchers have devoted considerable effort to efforts to understand the conditions promoting platform growth and stimulating network effects. For instance, a firm may employ a seeding strategy [30] or staged strategy [13] to render the services immediately relevant for at least those on one side of the relationship. With these users attracted to the platform, their partners, on the other side, will follow. Other strategies focus on subsidized use and product giveaways [9, 29], which create financial incentives for one party - again, with those on the other side following in their turn. In contrast, a marquee strategy focuses on key users on either side, whose participation is deemed important enough to make or break the platform's growth [30]. External pressure exerted by focal firms on their trading partners represents is a crucial mechanism for platform growth, especially in the realm of B2B connectivity platforms. We address relevant literature on this matter next.

\subsection{External pressure to adopt B2B connectivity platforms}

Li et al. [22] articulate three sets of factors with potential to affect a firm's decision to adopt and deploy B2B connectivity platforms: decision-object factors such as usefulness and complexity, decision-entity factors such as resources and risk propensity, and contextual factors such as trading partners' convergent influences and pressure from the external environment. Focusing on contextual factors, a considerable body of literature has addressed external environmental pressure in the general context of interorganizational information systems $[6,17,35]$ and the specific one of electronic invoicing [19, 31].

Interorganizational information system (IOS) studies focus on coercive enforcement, wherein a more powerful trading partner aims to dictate the IOS deployment in the business relationship [6, 35]. Alternatively, some IOS studies address external pressure in terms of competitive pressure, which presumes competing market forces coercing the firm to adopt the IOS $[6,17]$. Studies of electronic invoicing highlight recent developments favoring open standards [41] and the resulting greater interoperability [31]. In this context, several researchers have found benefit in conducting configurational analysis [19, 23] suggesting that the adoption of electronic invoicing is dependent on the focal firm's networks of trading partners.

The literature has not, however, taken into account the nuances of persuasion. Persuasion has been approached predominantly from the enforcement angle, with limited regard for the fact that some persuasion takes a non-coercive form - e.g., subtle enticement, gentle nudging, or informing about the benefits of the technology. This gap led us to attempt to provide a richer view of persuasion, articulating its particular forms with an eye to operationalizing them in the context of electronic invoicing.

\section{The empirical study}

To address our research question and study the impact of enticement and enforcement on organizational information systems' deployment, we sought to gather empirical data in a setting where both types of pressure would emerge naturally. Hence, we chose to examine organizations' deployment of electronic invoicing, a technology that enjoys considerable network effects, in that the benefits that "e-invoicing" brings to the firm accrue in tandem with the number of its trading partners 
that end up using electronic invoicing. The latter factor has led many organizations (both private and public) to start pushing their trading partners toward electronic invoicing platforms [32].

We chose to focus on two specific forms of persuasion occurring between customers and suppliers: enticement and enforcement. Since electronic invoicing enables the party receiving the invoice (the customer) to streamline and improve the process of handling incoming invoices, greater benefits of e-invoicing typically flow to the customer side [18]. Although suppliers too can gain some benefits from moving over to electronic invoicing and the associated adoption of the relevant $\mathrm{B} 2 \mathrm{~B}$ connectivity platform (e.g., better tracking afforded by digital invoices, automated matching of the payments received against one's sales invoices, and improved workflow overall), these gains are considerably smaller than those reaped by the invoice recipient, which - via "straight-through invoice processing" - can offload large amounts of work from the laborious processes of purchase invoices' reception, processing, and payment. For example, with the threeway-matching principle, ${ }^{1}$ a buyer that receives an electronic invoice may completely automate the processing for that specific invoice. This asymmetric benefit distribution leads to customers being more enthusiastic about deploying electronic invoicing than suppliers are about stepping aboard. This enthusiasm on customers' part has led them to adopt an industry practice of putting pressure on their suppliers to adopt electronic invoicing. ${ }^{2}$ Against this backdrop, we examine the impact of the pressure they place on their suppliers to implement e-invoicing such that the suppliers will start sending invoices to them in electronic format.

\subsection{Collection of the data}

We chose to gather data from suppliers, probing (i) their ability to send electronic invoices and (ii) the extent of enticement and enforcement they had experienced from customers with regard to adopting electronic invoicing for their sales-invoice processes. The data were collected in collaboration with the Federation of Finnish Entrepreneurs (FFE), which is the largest entrepreneur and SME association in Finland,

\footnotetext{
${ }^{1}$ Three-way-matching is the practice of matching the data content of a purchase order, an invoice, and a delivery note. If the data of all three documents (the amounts and product/service data) match, the invoice can be processed automatically without any human intervention. This is made possible by the purchase order already including all the posting information necessary for processing the invoice and posting it to bookkeeping systems. Among the global leaders employing the three-way matching principle are Heineken (e.g., https:/www.basware.com/en-gb/blog/february-2019/heinekenautomates-invoice-processing-with-basware/) and UPM-Kymmene
}

representing 115,000 enterprises. We sampled 700 firms at random from among its member enterprises, which have between 10 and 250 employees (in line with the European Union's definition of an SME). There were two main reasons for focusing on SMEs. First, we sought to exclude the largest, publicly listed companies from our sample. Presumably, their position and economic influence on their trading partners would render any pressuring efforts conceptually different from those exerted on an SME. Second, we wished to exclude the smallest firms from our sample since, with some having only one or two trading partners, they might not contribute to the richness of the empirical setting. We composed an online survey which was distributed via email to the sample of $700 \mathrm{SME}$ companies by FFE.

\subsection{The data and methodology}

Our dependent variable was the degree of electronic invoicing in sales invoicing. For efficiency reasons, it is common industry practice for firms to track the extent of electronic invoicing with regard to both purchase and sales invoices. Thus, we asked the respondents to indicate the percentage of their firm's customer companies that receive invoices in electronic format. For our main independent variables, we used three Likert-scale items addressing enticement and three items for enforcement. In the absence of preexisting instruments to measure enticement and enforcement, we developed items for the constructs by drawing on the process presented by Chin et al. [5]. Firstly, we developed a set of initial items for each construct. Then, we critically evaluated each item and discussed whether it is an appropriate reflection of the corresponding construct. When the authors had achieved consensus, we had four other IS scholars classify the mixed set of items into two groups, after which we asked them to elaborate on what was common to the items in each group. Their responses were in line with our assessments: they found some of the items to represent enforcement or coercion while others were "softer" in nature and more enticement-oriented. The first phase was followed by an exploratory one for testing the instrument and, if so required, refining it. Finally, confirmatory analysis was conducted, resulting in the final constructs. For the

(http://epub.lib.aalto.fi/fi/ethesis/pdf/13186/hse ethesis 13186.pdf). The business case for three-way matching is considerable, since invoices' processing is a costly process: industry estimates put the cost at, on average, 30 euros per invoice processed [18].

${ }^{2}$ Illustrating the pressure applied, Finnish government agencies only accept electronic invoices from their

suppliers, as indicated at https://www.valtiokonttori.fi/en/service/gov ernment-electronic-invoicing-website/\#invoicing-finnishgovernment-agencies. 
control variables, we used various items related to company size, the systems in use, industry, invoicing volume, and e-invoicing intention. Table 1 summarizes the final constructs and the control variables employed in the empirical study.

\section{Table 1. The variable constructs}

\begin{tabular}{|l|l|}
\hline Construct (variable) & \multicolumn{1}{c|}{ Question } \\
\hline $\begin{array}{l}\text { Degree of electronic } \\
\text { invoicing in sales } \\
\text { invoicing } \\
\text { (e invoicing) }\end{array}$ & $\begin{array}{l}\text { The percentage of customer companies } \\
\text { that receive invoices in electronic format }\end{array}$ \\
\hline $\begin{array}{l}\text { Enforcement1 } \\
\text { stick1) }\end{array}$ & $\begin{array}{l}\text { Our customers have demanded that we } \\
\text { implement electronic invoicing. }\end{array}$ \\
\hline $\begin{array}{l}\text { Enforcement2 } \\
\text { (stick2) }\end{array}$ & $\begin{array}{l}\text { Our customers have pressured us to } \\
\text { implement electronic invoicing (e.g., by } \\
\text { threatening to impose additional fees for } \\
\text { paper invoices). }\end{array}$ \\
\hline $\begin{array}{l}\text { Enforcement3 } \\
\text { (stick3) }\end{array}$ & $\begin{array}{l}\text { Our customers have coerced us to } \\
\text { implement electronic invoicing. }\end{array}$ \\
\hline $\begin{array}{l}\text { Enticement1 } \\
\text { (carrot } 1)\end{array}$ & $\begin{array}{l}\text { Our customers have informed us about } \\
\text { the financial and environmental benefits } \\
\text { of electronic invoicing. }\end{array}$ \\
\hline $\begin{array}{l}\text { Enticement2 } \\
\text { (carrot2) }\end{array}$ & $\begin{array}{l}\text { Our customers have offered enticement } \\
\text { for implementing electronic invoicing. }\end{array}$ \\
\hline $\begin{array}{l}\text { Enticement3 } \\
\text { (carrot3) }\end{array}$ & $\begin{array}{l}\text { Our customers have encouraged us to } \\
\text { implement electronic invoicing. }\end{array}$ \\
\hline $\begin{array}{l}\text { Company size } \\
\text { (employees) }\end{array}$ & $\begin{array}{l}\text { How many employees does your } \\
\text { company employ? }\end{array}$ \\
\hline $\begin{array}{l}\text { Company turnover } \\
\text { (turnover) }\end{array}$ & $\begin{array}{l}\text { What was the last reported annual } \\
\text { turnover of your company? }\end{array}$ \\
\hline $\begin{array}{l}\text { Customer base } \\
\text { (customers })\end{array}$ & $\begin{array}{l}\text { How many sales invoices do you send } \\
\text { per year (incl. all customers)? } \\
\text { (approximate) }\end{array}$ \\
\hline $\begin{array}{l}\text { Invoicing volume } \\
\text { (invoices })\end{array}$ & $\begin{array}{l}\text { How many customers do you send sales } \\
\text { invoices to? (approximate) }\end{array}$ \\
\hline $\begin{array}{l}\text { Cloud system } \\
\text { (cloudsys })\end{array}$ & $\begin{array}{l}\text { Does your company use a cloud-based } \\
\text { accounting system? }\end{array}$ \\
\hline $\begin{array}{l}\text { E-invoicing intentions } \\
\text { (e intents })\end{array}$ & $\begin{array}{l}\text { Are you currently increasing the number } \\
\text { of e-invoices in your sales invoicing? } \\
\text { Are you planning to increase the number } \\
\text { of e-invoices in your sales invoicing in } \\
\text { the near future? }\end{array}$ \\
\hline
\end{tabular}

After screening for complete responses, we were left with 121 observations to use in our empirical analysis. Table 2 presents summary statistics associated with the degree of e-invoicing. The mean and median degrees reported are, respectively, $63 \%$ and $71 \%$, with a standard deviation of 29 percentage points. The coefficient of variation (0.46) implies considerable differences in the respondent-reported degrees of einvoicing in sales invoicing.

Table 2. Non-transformed variables

\begin{tabular}{|l|r|r|r|r|r|}
\hline & Mean & Median & Std. dev. & Min. & Max. \\
\hline e_invoicing & 62.76 & 71.00 & 29.11 & 0.00 & 100.00 \\
\hline stick1 & 3.16 & 3.00 & 1.35 & 1.00 & 5.00 \\
\hline
\end{tabular}

\begin{tabular}{|l|r|r|r|r|r|}
\hline stick2 & 2.01 & 1.00 & 1.20 & 1.00 & 5.00 \\
\hline stick3 & 1.84 & 1.00 & 1.09 & 1.00 & 5.00 \\
\hline carrot1 & 2.96 & 3.00 & 1.30 & 1.00 & 5.00 \\
\hline carrot2 & 2.89 & 3.00 & 1.25 & 1.00 & 5.00 \\
\hline carrot3 & 3.12 & 3.00 & 1.27 & 1.00 & 5.00 \\
\hline employees & 35.59 & 13.00 & 97.09 & 8.00 & 625.00 \\
\hline turnover & 2690083 & 1000001 & 6827864 & 1 & 50000001 \\
\hline customers & 292 & 100 & 1022 & 2 & 10000 \\
\hline invoices & 2988 & 800 & 13955 & 20 & 150000 \\
\hline cloudsys & 0.50 & 1.00 & 0.50 & 0.00 & 1.00 \\
\hline e_intents & 0.71 & 1.00 & 0.46 & 0.00 & 1.00 \\
\hline pweight & 685.57 & 425.84 & 625.73 & 53.00 & 6264.00 \\
\hline
\end{tabular}

\section{Analysis and findings}

For our main analysis, we applied linear multiple regression models to identify the importance of each independent variable in a joint statistical setting. For the linear estimators to be well specified, some variables were transformed so as to be consistent with the underlying statistical assumptions. Firstly, the volumebased control variables, having highly skewed distributions, were log-transformed and winsorized at the one-percent level. Secondly, the independent variables were coded into first-order orthogonal polynomials, which maintain the ordinal relationship of the Likert scale and provide for orthogonal contrast with the lower- and higher-order terms. Thirdly, new control variables, productivity and intensity, replaced the original and mildly multicollinear variables turnover and invoices, respectively, without a loss of information. The variable productivity is the central difference between company turnover and the number of employees. In that it, in effect, measures the weighted turnover-per-employee ratio and is orthogonal to employees. Along similar lines, intensity is the orthogonal difference between invoicing volume (invoices) and the number of customers (customers). The described orthogonalization procedures reduce Variance Inflation Factors of the multiple regression models to very close to 1 .

Our initial descriptive analysis of both persuasion constructs (enforcement and enticement) revealed differences among the three items. This prompted us to inspect the wording of the various items, and we confirmed that the first item in both constructs was indeed relatively mild and the third was more severe (for example, with the enforcement construct's items corresponding to the following in English, in ascending severity: "demanded [that the respondent] implement," "pressured [the respondent] to implement," and "coerced [the respondent] to implement"). Therefore, for each type of persuasion, we will refer to the items in 
terms of the distinct level represented (the first item, the mildest, being referred to also as "low"; the second as "medium"; and the final, severe one as "high").

We estimated the multiple-regression models by using a generalized linear model (GLM) framework with a logit link function. In the estimation, each observation is weighted by its survey sampling probability, to permit population-level inferences. ${ }^{3}$ The goodness-of-fit of each model was assessed by means of three statistics: $R^{2}$, the predictive power of the model as the square of the correlation between the observed and the predicted values [40]; $F$-statistic, for an overall $F$ test of the regression slopes; and the root mean square error, or $R M S E$, of the predicted response relative to that observed.

We considered four distinct model specifications. The reduced model tests for the direct effects of the independent variables, without including the control variables. Secondly, the baseline model includes both the independent and control variables. The industry model, in turn, is identical to the baseline model in terms of the coefficient magnitudes but has the coefficient standard errors clustered by industry instead of for the individual. Finally, the pca model replaces the six independent variables with four principal components. In an additional step, we applied varimax rotation to convert the principal loadings into a simpler, more interpretable structure. Accordingly, the variables for moderate and high enforcement (stick2 and stick3) are replaced by their average (stick23) in the pca model, and, correspondingly, the variables for moderate and high enticement (carrot 2 and carrot 3 ) are replaced with carrot23. The variables for low levels of enforcement and enticement, stick1 and carrot1, remain unchanged. The four rotated components explain $94 \%$ of the total variance in the six independent variables, indicating that the rotation results in only a marginal loss of explanatory power in the context of the pca model.

Table 3 presents the results for various multipleregression specifications. Overall, the explanatory power of the full-scale models is reasonably high, with the $R^{2}$ value rising above $22 \%$ and the $F$-statistics for all the models showing statistical significance at the one-percent level. The estimated parameters for the independent variables are stable and sign-consistent across all the models. The coefficients for the control variables are also sign-consistent, and, as a whole, they explain an additional 13.8 percentage points of the

\footnotetext{
${ }^{3}$ Probability weights are used to weight the sample back to the population from which it was drawn. The 121 companies represented in the sample were split into eight size buckets, with upper bounds of 4, 9, 19, 49, 99, 249, 499, and 999 employees. The probability weight for each observation is calculated as $N_{i} / n_{i}$, where $i$ indexes the size bucket of company $i, N_{i}$ is the number of companies in the population, and $n_{i}$ is the number of companies in the sample. The
}

variation (reduced $R^{2}$ vs. baseline $R^{2}$ ), which supports our choices for the control variables. Importantly, the inclusion of the control variables does not render the independent variables statistically insignificant. This implies that the control variables and independent variables explain separate sources of variation.

\section{Table 3. Multiple-regression analysis}

\begin{tabular}{|c|c|c|c|c|}
\hline \multirow{2}{*}{$\begin{array}{l}\text { Model } \\
\text { Variable }\end{array}$} & reduced & baseline & industry & $p c a$ \\
\hline & & & & \\
\hline \multirow[t]{2}{*}{ stickl } & $1.099^{* * *}$ & $1.079^{* * * *}$ & $1.079^{*}$ & $1.065^{* * *}$ \\
\hline & $(3.21)$ & $(3.08)$ & $(2.33)$ & $(3.41)$ \\
\hline \multirow[t]{2}{*}{ stick2 } & -0.115 & -0.358 & -0.358 & \\
\hline & $(-0.26)$ & $(-1.01)$ & $(-0.64)$ & \\
\hline \multirow[t]{2}{*}{ stick3 } & -0.536 & -0.309 & -0.309 & \\
\hline & $(-1.20)$ & $(-0.76)$ & $(-0.45)$ & \\
\hline \multirow[t]{2}{*}{ carrot1 } & $0.642^{* *}$ & $0.589^{*}$ & $0.589^{*}$ & $0.591^{*}$ \\
\hline & $(2.00)$ & $(1.80)$ & $(2.10)$ & $(1.82)$ \\
\hline \multirow[t]{2}{*}{ carrot2 } & -0.395 & -0.118 & -0.118 & \\
\hline & $(-0.69)$ & $(-0.19)$ & $(-0.25)$ & \\
\hline \multirow[t]{2}{*}{ carrot3 } & -0.334 & -0.464 & -0.464 & \\
\hline & $(-0.54)$ & $(-0.69)$ & $(-1.47)$ & \\
\hline \multirow[t]{2}{*}{ stick23 } & & & & $-0.333^{*}$ \\
\hline & & & & $(1.77)$ \\
\hline \multirow[t]{2}{*}{ carrot 23} & & & & -0.300 \\
\hline & & & & $(-1.53)$ \\
\hline \multirow[t]{2}{*}{ employees } & & $0.475^{* * *}$ & $0.475^{* *}$ & $0.475^{* * *}$ \\
\hline & & $(3.69)$ & $(2.59)$ & $(3.70)$ \\
\hline \multirow[t]{2}{*}{ productivity } & & $0.211^{*}$ & $0.211^{*}$ & $0.213^{*}$ \\
\hline & & $(1.65)$ & $(1.96)$ & $(1.67)$ \\
\hline \multirow[t]{2}{*}{ customers } & & $-0.196^{* * *}$ & -0.196 & $-0.196^{* * *}$ \\
\hline & & $(-2.85)$ & $(-1.80)$ & $(-2.84)$ \\
\hline \multirow[t]{2}{*}{ intensity } & & 0.120 & 0.120 & 0.120 \\
\hline & & $(0.89)$ & $(1.18)$ & $(0.88)$ \\
\hline \multirow[t]{2}{*}{ cloudsys } & & $0.594^{* * *}$ & $0.594^{* *}$ & $0.580^{* * *}$ \\
\hline & & (2.69) & (3.30) & $(2.76)$ \\
\hline \multirow[t]{2}{*}{$e$ intents } & & -0.120 & -0.120 & -0.084 \\
\hline & & $(-0.40)$ & $(-0.29)$ & $(-0.33)$ \\
\hline$R^{2}$ & 0.0920 & 0.228 & 0.228 & 0.224 \\
\hline RMSE & 0.285 & 0.270 & 0.270 & 0.268 \\
\hline$F$-statistic & 3.165 & 4.205 & 4.205 & 4.940 \\
\hline
\end{tabular}

The coefficients of the independent variables show a clear pattern across effort levels. Overall, the estimated impacts of the variables for mild persuasion efforts, stick1 and carrot1, are positive and of large magnitude. In contrast, the variables for moderate and still greater efforts, identified by the suffixes "2" and "3", are negative but generally insignificant. The sole exception in this regard appears to be the pca model, in which the combined variable for moderate to high enforcement (stick23) is borderline statistically

median probability weight in our sample is 425 , indicating that the median observation in it represents 425 companies of similar size in the population. We use survey estimation procedures in Stata's svy module. Data on Finnish companies were obtained from Statistics Finland:

https://www.tilastokeskus.fi/tup/suoluk/suoluk yritykset en.html. 
significant $(-0.467, t=-1.77)$. In comparison of the two low-intensity persuasion efforts, the variable for light enforcement, stick1 (1.065 to $1.099, t>=2.33$ ), seems to have a larger impact than the one for light enticement, carrot1 $(0.589$ to $0.642, t>=1.80)$.

Four of the control variables are generally significant across all model specifications, while two are consistently insignificant. Company size (0.475), measured as the natural logarithm of the number of employees, and the use of cloud-based accounting systems (0.580 to 0.594) exhibit a robust positive association with the dependent variable. Company productivity, measured as the natural logarithm of turnover per employee, too shows a positive correlation with the dependent variable, albeit less robustly $(0.211$ to 0.213$)$. The number of customers is negatively associated with e-invoicing (-0.197 to -0.196$)$.

Next, we re-estimated the pca model separately for each characteristic-based subgroup to gain further insight into the mediating roles of respondent characteristics. Also, this allowed us to test whether our findings for the overall sample hold across various respondent subgroups. Under this approach, we chose a set of control variables with potential to display a mediating role and split the full sample into two subgroups, low and high, corresponding to the sample median of each control variable. Under the null hypothesis, the estimated regression parameters for the low and high samples are pairwise identical and reveal no further insights vis-à-vis the full-sample model. Under the alternative hypothesis, one or more parameters exhibit a regression discontinuity across the median split, uncovering new perspectives on the dependent variable's precise relationship with enforcement and enticement.

Table 4 presents the results for the split-sample analysis based on company size (turnover), customer base (customer), invoicing intensity (intensity), and use of cloud-based accounting systems (cloudsys). Control variables are included in regressions but omitted from the table for brevity.

Table 4. Median split results

\begin{tabular}{|l|l|l|l|l|}
\hline \multirow{2}{*}{ Variable } & \multicolumn{2}{|c|}{ turnover } & \multicolumn{2}{c|}{ customer } \\
\cline { 2 - 5 } & low & high & low & high \\
\hline \multirow{3}{*}{ stick1 } & 0.630 & $1.324^{* * *}$ & $0.901^{*}$ & $0.933^{* *}$ \\
\cline { 2 - 5 } & $(0.82)$ & $(4.33)$ & $(1.81)$ & $(2.13)$ \\
\hline \multirow{3}{*}{ carrot1 } & 0.166 & $-0.679^{* *}$ & -0.273 & $-0.800^{* *}$ \\
\cline { 2 - 5 } & $(0.27)$ & $(-2.27)$ & $(-0.55)$ & $(-2.17)$ \\
\hline carrot23 & 0.219 & $0.723^{*}$ & $0.884^{* *}$ & 0.183 \\
\cline { 2 - 5 } & $(0.33)$ & $(1.94)$ & $(2.42)$ & $(0.20)$ \\
\hline$R^{2}$ & -0.418 & -0.477 & -0.596 & 0.211 \\
\hline RMSE & $(-0.58)$ & $(-1.63)$ & $(-1.50)$ & $(0.46)$ \\
\hline F-statistic & 0.203 & 0.186 & 0.225 & 0.0685 \\
\hline & 0.507 & 0.354 & 0.359 & 0.560 \\
\hline
\end{tabular}

\begin{tabular}{|l|l|l|l|l|}
\hline & \multicolumn{2}{|c|}{} & & \multicolumn{2}{c|}{} \\
\hline & \multicolumn{2}{|c|}{ intensity } & \multicolumn{2}{c|}{ cloudsys } \\
\hline \multirow{3}{*}{ stick1 } & low & high & no & yes \\
\hline \multirow{3}{*}{ stick23 } & $1.484^{* * *}$ & 0.423 & $1.494^{* * *}$ & 0.157 \\
\cline { 2 - 5 } & $(3.39)$ & $(1.06)$ & $(3.60)$ & $(0.26)$ \\
\hline \multirow{3}{*}{ carrot1 } & $-0.867^{* * *}$ & 0.612 & -0.336 & -0.288 \\
\cline { 2 - 5 } & $(-3.33)$ & $(1.04)$ & $(-0.88)$ & $(-0.64)$ \\
\hline \multirow{3}{*}{ carrot23 } & 0.325 & $1.156^{*}$ & 0.401 & $0.916^{*}$ \\
\cline { 2 - 5 } & $(0.81)$ & $(1.89)$ & $(0.91)$ & $(1.78)$ \\
\hline \multirow{2}{*}{$R^{2}$} & -0.328 & $-0.805^{*}$ & -0.557 & -0.023 \\
\hline RMSE & $(-0.76)$ & $(-1.73)$ & $(-1.41)$ & $(-0.06)$ \\
\hline F-statistic & 0.203 & 0.121 & 0.187 & 0.119 \\
\hline & 0.425 & 0.426 & 0.424 & 0.433 \\
\hline
\end{tabular}

In the subsample estimations, low levels of enforcement generally have a larger impact than mild enticement, with two notable exceptions. The first of these involves firms with high invoicing intensity (the number of invoices divided by the number of customers); the low- and high-strength enticement variables (carrot1 and carrot23) are both larger in magnitude than their enforcement counterparts (stick1 and stick23). The exact opposite holds in the lowintensity model, where the enforcement coefficients are larger and statistically significant. The second exception is seen with the cloudsys median split, where the variable for mild enticement has a larger estimated impact than does the mild-enforcement variable for the high sample while the results are vice versa for the low sample.

The models for low- and high-turnover companies are presented in the first two columns of numbers in Table 4 . The $F$-statistic shows that the high model is statistically dominant, indicating that it is mainly highturnover companies that drive the parameter estimates in the pca model. The model for smaller companies, low, is not statistically significant as a whole, although the estimated impacts of intensity $(-0.298, t=1.74)$ and cloudsys $(-0.979, t=1.66)$ are twice as large as they are in the high-turnover model. As for the independent variables, the high-turnover model predicts similar but stronger positive effects on mild-level efforts than the pca model does, along with strong negative effects on strong enforcement efforts. The $\mathrm{R}^{2}$ measurements imply that the two models explain the same amount of variation in the low and high sample, in relative terms, although there seems to be much more variation in the low sample (RMSE $=0.507)$.

The customer median split analysis suggests that both low-effort variables (stick1 and carrot1) are positively associated with the dependent variables in the low customer model, while only stick 1 and stick 2 are significantly impactful in the larger-customer-base sample (high). 


\section{Discussion}

We set out to explore the influence of external pressure in the act of onboarding trading partners to $\mathrm{B} 2 \mathrm{~B}$ connectivity platforms. While previous research has examined the impact of perceived institutional pressure on IOS adoption [38], it has not delved deeply into the effects of more concrete pressuring experiences. Moreover, specific nuances of pressure ranging from soft/light persuasion to strong coercion have not been distinguished, even though scholars have expressed interest in understanding particular types of persuasive messages in the context of multi-sided platforms, since such communications are expected to help draw users to the platforms [37]. In response to these gaps, we investigated the effect of enticement and enforcement in getting a focal firm's suppliers to adopt a given connectivity platform for submission of the suppliers' transaction documents (invoices) in the desired standardized electronic form. Overall, our findings suggest that enforcement has greater influence than enticement: sticks work better than carrots. This finding has several implications for theory and management practice, as discussed below.

\subsection{Implications for theory}

It was not entirely unexpected that we found enforcement to work better than enticement in customers' endeavors to get their trading partners (i.e., suppliers) to submit invoices in electronic format. We argue that two inherent characteristics of e-invoicing are behind this. Firstly, e-invoicing is not the core function of most firms; rather, it is a support function, a back-end process. Firms' top executives and decision-makers typically have a relatively short attention span when tackling concerns related to such back-end processes that tend to escape their radar [31]. We link this finding to the two routes identified in the ELM approach [33]: the main ("central") route, on which receivers carefully process message arguments, and the peripheral one, which involves relying on mental shortcuts for coming to a conclusion. From our findings, it seems that triggering the central route for a supplier requires the stakeholder to employ enforcement. Secondly, the gains from e-invoicing are asymmetric in that most of the benefits are enjoyed by the party receiving the invoice: moving to e-invoicing lets the buyer streamline and automate its invoice-processing practices and achieve significant cost savings. A corresponding connection between asymmetric division in the benefits brought by digitalization and a need for enforcement has been identified in other, similar contexts such as XBRLbased government reporting.
Our fine-grained analysis of the data reveals two exceptions to this overriding effect of enforcement as opposed to enticement. Enticement was found to be more effective than enforcement when exerted on highinvoicing-intensity organizations and heavy users of cloud computing. Regarding the first category, we argue that organizations with high invoicing intensity tend to have closer business relationships with their customers, resulting from relatively extensive interaction with the customers (at least in terms of business-transaction documents). We theorize that in such relationships, enticement seems to function better than enforcement does for persuading one's business partners to sign up for the relevant B2B connectivity platform. Secondly, considering the use of cloud-based technologies, one can interpret the use of such solutions as a proxy for an organization's level of technology-readiness. For cloudapplication-intensive firms, enticement might be a sufficient trigger for adopting e-invoicing, so blunt enforcement instruments may not be needed. Notwithstanding all these interpretations, our findings point toward the contingent nature of IOS adoption: there exists no universal or single best approach.

\subsection{Management implications}

If wishing to harness the benefits of network technologies, managers must find salient ways to maximize the number of nodes in their networks. Academic and practitioner literature already provide a plethora of insights with regard to mechanisms that could be used for this purpose, as discussed in our review of literature on platform-growth strategies. Our study was focused on one specific tool in this toolkit: external pressure in the form of enticement and enforcement. Interestingly, we found that, for both enticement and enforcement, lower levels of external pressure seemed to work better than stronger methods did. Thus, gentle enticement and gentle enforcement are more effective in bringing trading partners aboard B2B connectivity platforms. Our findings thus reveal that, when exerting pressure, managers need to be aggressive but not too aggressive; that is, while they must enforce the use of technologies, some limits to the enforcement are sensible. Accordingly, managerial mindfulness and sensitivity to context are called for in the design and application of pressuring methods.

When making management recommendations in light of our study's results, one must be mindful of our empirical context, with its asymmetry of benefits between the sender and the receiver of invoices. We encourage managers to address this by analyzing the potential lopsidedness of benefits between the two sides of the platform and devising their platform strategies accordingly. Enforcement is one option that managers 
should consider - context and the rules of the game permitting - when there exist critical user parties whose gains from starting to use the platform are significantly smaller than the other side's.

\subsection{Limitations and further research}

Like all studies, ours has its limitations. Firstly, we chose to focus on a technology that enjoys considerable network effects: B2B connectivity platforms and, more specifically, e-invoicing. The conclusions from the study and its implications are heavily influenced by this specific empirical context characterized by power imbalances and asymmetric rewards. For greater generalizability and a broader picture, further studies could cover a wider selection of technologies with larger sample sizes and perhaps note the varying effects of enticement and enforcement across different classes of technologies. Secondly, our empirical evidence came from Finland, in the region of the world with the highest degree of e-invoicing. While this choice allowed us to study e-invoicing in a naturally rich empirical setting, further research could look into the subject in geographical settings where e-invoicing is less common. Thirdly, while we focused on trading-partnerwielded enticement and enforcement, we acknowledge that external pressure can be exerted on firms from various other quarters - as represented by government regulation, third-sector actors such as non-governmental organizations, etc. Further research could study the impact that these players may have on individual firms considering subscribing to a particular B2B connectivity platform. Also, the somewhat coarse division of external pressure into enticement and enforcement needs further research by probing the nuances of the two main types and their influence upon different IT governance modes [39]. Finally, the cross-sectional nature of our study imposes limits on the conclusions that may safely be drawn from its results. While a link between pressure and degree of e-invoicing may be theoretically justified, we cannot make definitive claims as to the direction of causality between the two. For instance, it is possible that another, unknown variable could explain both the pressure experienced and degree of e-invoicing within our sample, rendering the two variables of interest correlated but not causally related. That said, we find that a link between the two is the most plausible explanation for the variation observed. We nevertheless encourage researchers to pursue longitudinal and experimental approaches that allow a full causal examination of pressuring's effects.

\section{References}

[1] Ali, M., L. Zhou, L. Miller, and P. Ieromonachou, "User resistance in IT: A literature review", International Journal of Information Management 36(1), 2016, pp. 35-43.

[2] Bemelmans-Videc, M.L., R.C. Rist, and E. Vedung, Carrots, Sticks and Sermons: Policy Instruments and Their Evaluation, Transaction Publishers, New Brunswick, NJ, 2010.

[3] Besson, P., and F. Rowe, "Strategizing information systems-enabled organizational transformation: A transdisciplinary review and new directions", Journal of Strategic Information Systems 21(2), 2012, pp. 103-124. [4] Brynjolfsson, E., "The productivity paradox of information technology", Communications of the ACM 36(12), 1993, pp. 67-77.

[5] Chin, W.W., A. Gopal, and W.D. Salisbury, "Advancing the Theory of Adaptive Structuration: The Development of a Scale to Measure Faithfulness of Appropriation", Information Systems Research 8(4), 1997, pp. 342-367. [6] Chwelos, P., I. Benbasat, and A.S. Dexter, "Empirical Test of an EDI Adoption Model", Information Systems Research 12(3), 2001, pp. 304-321.

[7] DiMaggio, P.J., and W.W. Powell, "The Iron Cage Revisited: Institutional Isomorphism and Collective Rationality in Organizational Fields", American Sociological Review 48(2), 1983, pp. 147-160.

[8] Dwivedi, Y.K., D. Wastell, S. Laumer, et al., "Research on information systems failures and successes: Status update and future directions", Information Systems Frontiers 17(1), 2014, pp. 143-157.

[9] Eisenmann, T., G. Parker, and M. Van Alstyne, "Strategies for Two-Sided Markets", Harvard Business Review 84(10), 2006, pp. 92-101.

[10] Evans, D.S., and R. Schmalensee, "Markets with twosided platforms", In Issues in Competition Law and Policy. 2008, 667-693.

[11] Gilbert, C.G., "Unbundling the Structure of Inertia : Resource versus Routine Rigidity", Academy of Management Journal 48(5), 2005, pp. 741-763.

[12] Gordon, W.H., "Book review on 'Coercive Persuasion: A Socio-psychological Analysis of the "Brainwashing" of American Civilian Prisoners by the Chinese Communists", American Sociological Review 28(1), 1963, pp. 162.

[13] Hagiu, A., and T. Eisenmann, "A staged solution to the Catch-22”, Harvard Business Review 85, 2007, 25-26.

[14] Harjumaa, M., and H. Oinas-Kukkonen, "Persuasion theories and IT design", Lecture Notes in Computer Science (including subseries Lecture Notes in Artificial Intelligence and Lecture Notes in Bioinformatics), (2007).

[15] Hart, P., and C. Saunders, "Power and Trust: Critical Factors in the Adoption and Use of Electronic Data Interchange", Organization Science 8(1), 1997, pp. 23-42. [16] Heugens, P.P.M.A.R., and M.W. Lander, "Structure! agency! (and other quarrels): A meta-analysis of institutional theories of organization", Academy of Management Journal 52(1), 2009, pp. 61-85.

[17] Iacovou, C.L., I. Benbasat, and A.S. Dexter, "Electronic data interchange and small organizations: Adoption and impact of technology", MIS Quarterly 19(4), 1995, pp. 465485.

[18] Koch, B., E-Invoicing / E-Billing - opportunities in a challenging market environment, 2014.

[19] Kreuzer, S., "Explaining organizational susceptibility to 
coercive pressure: results from a field experiment on einvoicing IOIS adoption", Information Systems and eBusiness Management 15, 2017, pp. 159-195.

[20] Krisko, A., "The role of resistance in incorporating XBRL into financial reporting practices", International Journal of Accounting and Economics Studies 5(2), 2017, pp. $100-111$.

[21] Lapointe, L., and S. Rivard, "A Multilevel Model of Resistance to Information Technology Implementation", MIS Quarterly 29(3), 2005, pp. 461-491.

[22] Li, X., M.D. Troutt, A. Brandyberry, and T. Wang, "Decision factors for the adoption and continued use of online direct sales channels among SMEs", Journal of the Association for Information Systems 12(1), 2011, pp. 1-31. [23] Lyytinen, K., and J. Damsgaard, "Inter-organizational information systems adoption - a configuration analysis approach", European Journal of Information Systems 20(5), 2011, pp. 496-509.

[24] Lyytinen, K., and M. Newman, "A tale of two coalitions - marginalising the users while successfully implementing an enterprise resource planning system", Information Systems Journal 25(2), 2015, pp. 71-101.

[25] Marakas, G., and S. Hornik, "Passive resistance misuse: overt support and covert recalcitrance in IS implementation", European Journal of Information Systems 5(1996), 1996, pp. 208-219.

[26] Mignerat, M., and S. Rivard, "Positioning the institutional perspective in information systems research", Journal of Information Technology 24(4), 2009, pp. 369391.

[27] Norovuori, S., Factors in ICT Innovation's Diffusion from an Environmental Context Perspective: The Case of XBRL, Aalto University School of Economics, 2012. [28] Ondrus, J., A. Gannamaneni, and K. Lyytinen, "The impact of openness on the market potential of multi-sided platforms: A case study of mobile payment platforms", Journal of Information Technology 30(3), 2015, pp. 260275.

[29] Parker, G., and M. Van Alstyne, "Two-Sided Network Effects: A Theory of Information Product Design", Management Science 51(10), 2005, pp. 1494-1504. [30] Parker, G., M. Van Alstyne, and S. Choudary, Platform revolution: How Networked Markets Are Transforming the Economy--And How to Make Them Work for You, W.W. Norton \& Company Inc., New York, NY, 2016.
[31] Penttinen, E., M. Halme, K. Lyytinen, and N. Myllynen, "What Influences Choice of Business-to-Business Connectivity Platforms?", International Journal of Electronic Commerce 22(4), 2018, pp. 479-509.

[32] Penttinen, E., and T. Rinta-Kahila, "Onboarding customer companies to electronic invoicing platform developing a marketing and a partnering strategy for Tieto, an e-invoicing service provider", Journal of Information Technology Teaching Cases 7(1), 2017, pp. 43-50. [33] Petty, R.E., and J.T. Cacioppo, Attitudes and persuasion: Classic and contemporary approach, Dubuque, IA: Wm. C. Brown, 1981.

[34] Power, D., and R.L. Gruner, "Exploring reduced global standards-based inter-organisational information technology adoption", International Journal of Operations and Production Management 35(11), 2015, pp. 1488-1511. [35] Premkumar, G., and K. Ramamurthy, "The Role of Interorganizational and Organizational Factors on the Decision Mode for Adoption of Interorganizational Systems", Decision Sciences 26(3), 1995, pp. 303-336. [36] Scott, W.R., Institutions and organizations: Ideas and interests, SAGE Publications, Los Angeles, CA, 2008.

[37] Soliman, W., and T. Rinta-Kahila, "Unethical but not illegal: Uncovering the persuasive messages leveraged by providers of the 'real' online social impressions", 26th European Conference on Information Systems, 2018, pp. 117.

[38] Teo, H.H., K.K. Wei, and I. Benbasat, "Predicting Intention to Adopt Interorganizatonal Linkages: An Institutional Perspective", MIS Quarterly 27(1), 2003, pp. $19-49$.

[39] Xue, Y., H. Liang, and W.R. Boulton, "Information technology governance in information technology investment decision processes: The impact of investment characteristics, external environment, and internal context", MIS Quarterly 32(1), 2008, pp. 67-96.

[40] Zheng, B., and A. Agresti, "Summarizing the predictive power of a generalized linear model", Statistics in Medicine 19(13), 2000, pp. 1771-1781.

[41] Zhu, K., K.L. Kraemer, V. Gurbaxani, and S.X. Xu, "Migration To Open-Standard Interorganizational Systems: Network Effects, Switching Costs, and Path Dependency", MIS Quarterly 30(Special Issue: Standard Making), 2006, pp. 515-539. 